\title{
BACTERICIDAL EFFECTIVENESS OF FREEZE-CAST CERAMIC FILTERS IMPREGNATED WITH SILVER NANOPARTICLES
}

\author{
T. de M. Amadio ${ }^{1 *}$, D. Hotza ${ }^{1}$ and J. B. Rodrigues Neto ${ }^{1}$ \\ ${ }^{1}$ Graduate Program in Materials Science and Engineering (PGMAT), Federal University of Santa Catarina (UFSC), \\ Florianópolis, SC, Brazil.
}

(Submitted: June 5, 2017 ; Revised: December 19, 2017 ; Accepted: January 6, 2018)

\begin{abstract}
This work aimed to produce freeze-cast pellets of porous ceramic filters of alumina and kaolinite impregnated with silver nanoparticles and to test the efficiency of bactericidal effects. Silver nanoparticles were characterized by average particle size, zeta potential and TEM. After impregnation, leached water was analyzed by graphite furnace atomic absorption spectrometry (GFAAS) that showed an efficiency of more than $99.9 \%$ in silver impregnation. From SEM/EDS, it was possible to observe that the pellets have a homogeneous distribution of silver nanoparticles. A halo of inhibition detected by the disc diffusion test shows a strong bactericidal effect of the filters.

Keywords: Nanoparticles; Silver; Impregnation; Bactericidal effect.
\end{abstract}

\section{INTRODUCTION}

Nanomaterials are systems in which at least one dimension is $1-100 \mathrm{~nm}$ in length with particular physical and chemical properties and can be used in numerous applications. Particularly silver in the form of nanoparticles has efficient antimicrobial properties (Singh and Nalwa, 2011; Dash et al., 2012; Leon-Silva et al., 2016; Díaz-Soler et al., 2017).

Silver is often used as an antibacterial agent in order to provide a sanitary environment for the wound healing process. It is considered historically as one of the most frequently used antibacterial substances before the invention of antibiotics. The multiplicity of silver's bactericidal mechanisms gives it a wide range of effective applications in the inhibition of bacterial growth. The introduction of nanoparticles has allowed the scientific community to enhance the antibacterial properties of silver. The increased surface area of the nanoparticles in turn induces an increased rate of interaction between the test subjects and the ionic silver (Alexander, 2009; Nam et al., 2015; Bal et al., 2015; Dong et al., 2016; Mckevica et al., 2016; Amadio et al., 2017).

To quantify silver nanoparticles in suspension, a technique with a very low limit of detection is necessary, such as graphite furnace atomic absorption spectrometry (GFAAS). The graphite furnace is generally considered an ultratrace and microtrace analytical technique with limits of detection (LODs) in the low picogram range, precision of a few percent (relative standard deviation) and a dynamic range of about three orders of magnitude. In addition to its high sensitivity, it is unique in its ability to handle microsamples, including aqueous solutions, viscous liquids, slurries and even solids. GFAAS is an atomic spectroscopic technique in which a small sample is placed inside a graphite tube that is then resistively heated to accomplish sample desolvation (for liquid samples), ashing or charring (to decompose the sample and volatilize some of the matrix) and finally atomization (Holcombe, 2006).

\footnotetext{
*Email: tatiamadio@gmail.com
} 
Stoimenov et al. (2002) demonstrated that highly reactive metal oxide nanoparticles exhibit excellent biocidal action against Gram-positive and Gramnegative bacteria (Stoimenov et al., 2002; Sondi, 2004). One way to test the bactericidal properties in the filter pellets is the Disc Diffusion Test (also known as Kirby-Bauer antibiotic testing). This is a test of the antibiotic sensitivity of bacteria. It uses antibioticimpregnated pellets to test the extent to which bacteria are affected by those antibiotics (Biemer, 1973; Hudzicki, 2009). In this test, pellets containing antibiotic are placed on an agar plate where bacteria, Gram-positive or Gram-negative, have been placed, and the plate is left to incubate. In these tests, if an antibiotic stops the bacteria from growing or kills the bacteria, there will be an area around the pellet where the bacteria have not grown enough to be visible, which is called a zone or halo of inhibition (Mohanty, 2010; Shahzada et al., 2014).

Neomycin, the antibiotic used, is an aminoglycoside antibiotic produced during fermentation of Streptomyces fradiae with a high antimicrobial efficacy and broad antibacterial spectrum. It inhibits the growth of Gram-negative and Gram-positive bacteria (Adams et al., 1996; Ju et al., 2017).

Gram-positive bacteria are bacteria that give a positive result in the Gram stain test. Gram stain differentiates bacteria by the chemical and physical properties of their cell walls by detecting peptidoglycan, which is present in the cell wall of Gram-positive bacteria. Gram-positive bacteria retain the crystal violet dye and thus are stained violet, while the Gram-negative bacteria do not; after washing, a counterstain is added (commonly safranin or fuchsine) that will stain these Gram-negative bacteria a pink color (Holt, 1994).

Enterococcus faecalis is formerly classified as part of the group D Streptococcus system - is a Gram-positive, commensal bacterium inhabiting the gastrointestinal tracts of humans and other mammals. It is usually outnumbered by strictly anaerobic bacteria (Russell et al., 2001; Ryan et al., 2004).

Escherichia coli is a Gram-negative, anaerobic, rodshaped, coliform bacterium of the genus Escherichia that is commonly found in the lower intestine of warm-blooded organisms (endotherms) (Singleton, 1999; Olivier et al., 2010).

In this work an innovative approach for impregnation of porous ceramic pellets, which can be used as filters for water or wastewater treatment, is proposed. Filter elements are produced by freeze casting, in which silver nanoparticles are impregnated in order to optimize the reactive surface area and to enhance the bactericidal effects.

\section{MATERIALS AND METHODS}

Porous ceramic filter samples ( $20 \mathrm{~mm}$ diameter, 15 $\mathrm{mm}$ long) of alumina, CT 3000, provided by Almatis, and kaolinite, provided by Colorminas (alumina 35 $\%$ wt, kaolinite 25\% wt, Darvan $1.5 \%$ wt. and distilled water $38.5 \%$ wt.) were produced by freeze casting.

In the freeze-casting process, the ceramic slurry was poured into a mold in contact with a copper bar dipped in liquid nitrogen. The temperature decreases until freezing the slurry, forming ice crystals with entrapped ceramic particles. After freeze casting, samples were set into a freeze dryer (Liotop L102, Liobras) at $0.39 \mathrm{~atm}$ and $-50{ }^{\circ} \mathrm{C}$, during $48 \mathrm{~h}$. Then the system was heated up to room temperature at that pressure to allow the frozen water in the material to sublimate. Finally, the dried samples were sintered in an electrical furnace (EDG-1600, EDG), at $1550{ }^{\circ} \mathrm{C}$, with a heating rate of $5{ }^{\circ} \mathrm{C} / \mathrm{min}$, and dwell time of $2 \mathrm{~h}$ at the maximum temperature.

The samples were impregnated by dipping into an aqueous suspension of silver nanoparticles (NPAg925, Batch Ind 36), $1000 \mu \mathrm{g} / \mathrm{L}$ and $\mathrm{pH} 4$, provided by TNS (TechNano Solutions, Brazil). The average particle size was measured by direct light scattering (Zetasizer, Nanosizer - ZS, Malvern).

Silver nanoparticles were analyzed with a Transmission Electron Microscope (TEM, JEM 1011, JEOL), with maximum acceleration voltage, $100 \mathrm{kV}$ and magnification range, $800 \times$ to $600,000 \times$, and electron diffraction.

The samples were impregnated by dipping in a sealed borosilicate glass beaker, during $24 \mathrm{~h}$. After that, a thermal treatment was performed in the furnace $(\mathrm{J} 200$, Jung) with a constant rate of $5^{\circ} \mathrm{C} / \mathrm{min}$ and $2 \mathrm{~h}$ at $200^{\circ} \mathrm{C}$, to fix the silver nanoparticles (NPAg) in the sample.

Figure 1 shows the flow chart that summarizes the main process of this work, including impregnation.

The impregnated samples were coated with a thin layer of gold and characterized in a scanning electron microscope and by energy dispersive X-ray spectroscopy (SEM/EDS, TM3030, Hitachi). EDS was used to provide rapid qualitative/quantitative analysis of elemental composition and to form map profiles, showing the elemental distribution $(\mathrm{Ag})$ in the sample surface and fracture. The EDS was carried out in areas of homogeneous distribution and in areas of nanoparticle agglomeration.

For testing the efficiency of impregnation, a section of the impregnated pellets was dipped into water in a tube (centrifuge) or in a beaker (mechanical stirrer or ultrasonic bath). Those setups with harsher conditions than the normal water flow through the pellets were employed to simulate a longer life span of the filters. The amount of NPAg that was not detected in the leached water was considered to be still impregnated in the pellets. 


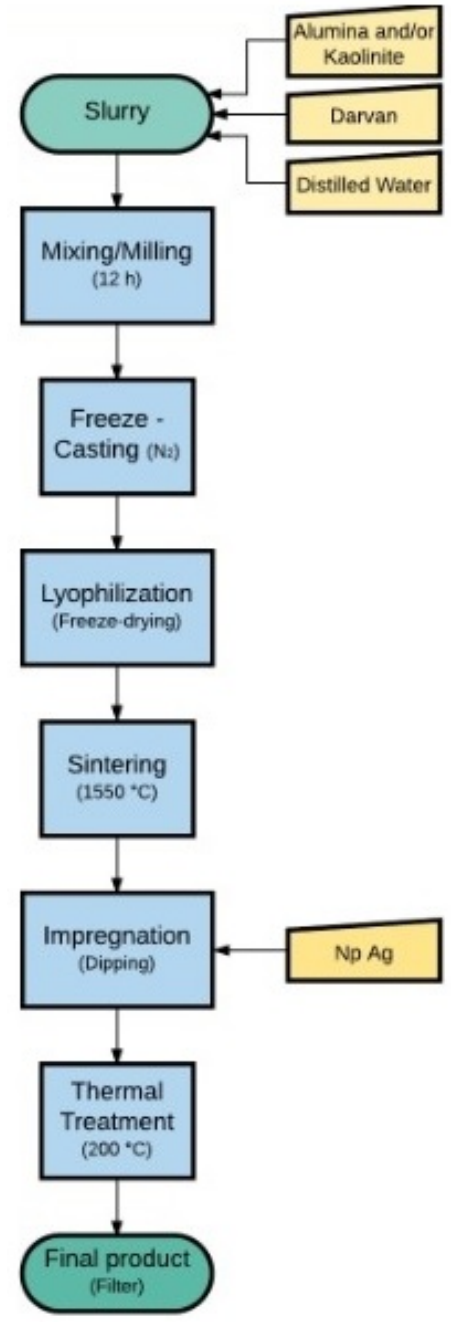

Figure 1. Flowchart of processing of filter elements including impregnation of silver nanoparticles.

The specific parameters applied to the leaching tests were:

- Mechanical stirring (overhead stirrer mixer) at $2000 \mathrm{rpm}$ during $1 \mathrm{~h}$ (MS 1); $2 \mathrm{~h}$ (MS 2); or $3 \mathrm{~h}$, after that $24 \mathrm{~h}$ resting, then more $3 \mathrm{~h}$ (MS 3-24).

- Centrifugation at $3600 \mathrm{rpm}$ during $15 \mathrm{~min}$ (CE 15) and $30 \mathrm{~min}$ (CE 30).

- Ultrasonic bath during 5 min (UL 5) and 15 $\min$ (UL 15).

To quantify silver in leached water, the same amount of water was collected from each tube or becker and analyzed by graphite furnace atomic absorption spectrometry (PinA Acle 900T, Perkin Elmer) with limit of detection (LoD) of $0.35 \mathrm{ng} / \mathrm{L}$ and limit of quantitation (LoQ) of $1.16 \mathrm{ng} / \mathrm{L}$. Lod and LoQ are terms used to describe the smallest concentration of an analyte that can be reliably measured by an analytical procedure.

To analyze the bactericidal effects of silver nanoparticles in the filter pellets, the Disc Diffusion Test (Kirby-Bauer antibiotic testing) was used according to a standard approved by the NCCLS
(National Committee for Clinical Laboratory Standards) (NCCLS, 2000). Two bacteria were chosen in this case: Escherichia coli (Gram-negative) and Enterococcus faecalis (Gram-positive).

Commercial pellets containing antibiotic (Neomycin), (Sensidisc, DME 5mcg/pellets), and ceramic filter pellets developed in this work (with and without NPAg) were set on an agar plate where bacteria (Escherichia coli (Gram-negative) and Enterococcus faecalis (Gram-positive)) have been placed, and the plate was left to incubate during $24 \mathrm{~h}$ at ca. $35^{\circ} \mathrm{C}$. It was necessary to test if the antibiotic stops the bacteria from growing or kills them. The results shows a halo of inhibition if silver has bactericidal effects.

\section{RESULTS AND DISCUSSION}

The particle size distribution of silver nanoparticles was determined by DLS (Figure 2). The average size is around $46 \mathrm{~nm}$ in the three measures, where some agglomeration of the particles in the micrometric range can be seen.

Figure 3 shows the curve of zeta potential versus $\mathrm{pH}$ of concentrated ( $\mathrm{Np} \mathrm{Ag} \mathrm{C)} \mathrm{and} \mathrm{dilute} \mathrm{(} \mathrm{Np} \mathrm{Ag} \mathrm{D)} \mathrm{silver}$

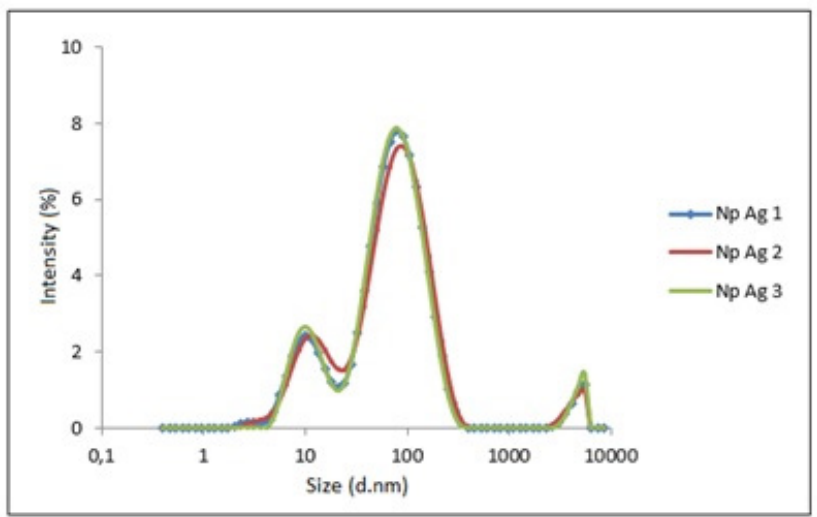

Figure 2. Size distribution of silver nanoparticles analyzed by DLS.

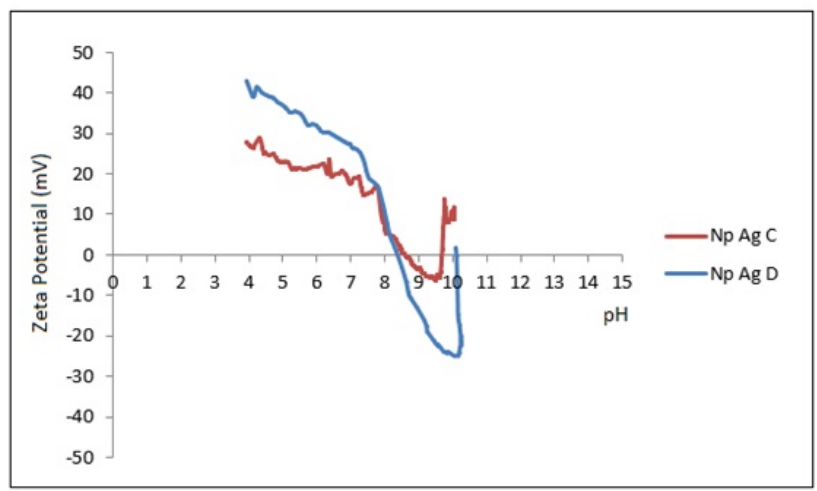

Figure 3. Zeta potential versus $\mathrm{pH}$, showing the isoelectric point of the concentrated and dilute silver nanoparticles suspensions. 
nanoparticle suspensions. In the dilute suspension, the original $\mathrm{pH}$ is higher (around 8), because it is diluted in water, so that it has a broader range of zeta potential than the original suspension, which has $\mathrm{pH} 4$ and a zeta potential of $-29.6 \mathrm{mV}$. The isoelectric point of the suspensions can be observed at $\mathrm{pH}$ around 8.5, which means that it is better to work with basic or acid suspensions, as far from $\mathrm{pH} 8.5$ as possible, because the suspensions are more stable in these ranges.

Silver nanoparticles were analyzed by TEM, as shown in the micrographs in Figure 4.

Different spots or textures are seen because of the difference in crystallographic orientation or interference. Using ImageJ (version $\mathrm{k}$ 1.45), some particles considered in the same crystallographic orientation were measured; the diameter of these particles was between $10 \mathrm{~nm}$ and $16 \mathrm{~nm}$, the average being $\sim 13 \mathrm{~nm}$ (with a coefficient of variation around $16 \%$ ). Figure 4D shows the distance between the transmitted point and the diffraction point, which determines the diffraction pattern. The final appearance of the sample is shown in Figure 5. The initial pellets did not suffer any crack or change in their structure or size after impregnation, thermal treatment, and repeated use with flowing water. The only remarkable observation was the color change after impregnation.

The impregnated samples were characterized by a scanning electron microscope and energy dispersive $\mathrm{x}$ - ray spectroscopy (SEM/EDS). Figure 6 shows the micrographs of the outer and fractured surfaces of the samples. Figure 6A shows the external surface of the impregnated sample, and Figure $6 \mathrm{~B}$, the fractured sample. It is difficult to see the nanoparticles in the structure because of their small size; in Figure 6C, the
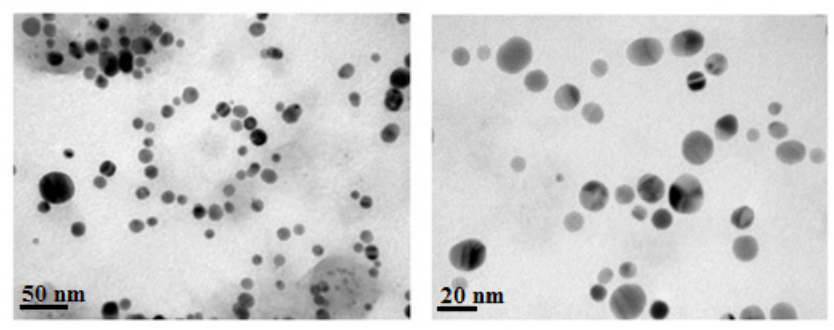

A)

B)
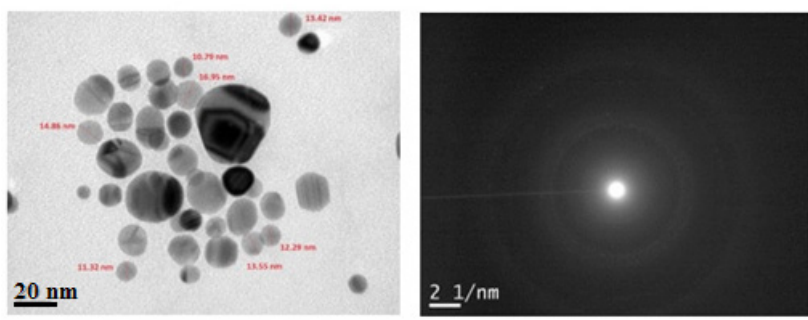

D)

C)

Figure 4. TEM micrographs of silver nanoparticles: A) $50 \mathrm{~nm}$, B) $20 \mathrm{~nm}$, C) $20 \mathrm{~nm}$ with some measures of particle size and D) electron diffraction pattern. fractured inner surface, it is possible to observe some agglomeration.

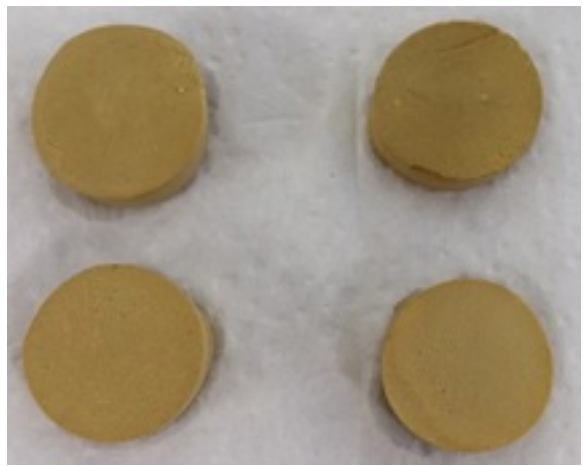

Figure 5. Final appearance of the sample impregnated with nano-Ag.

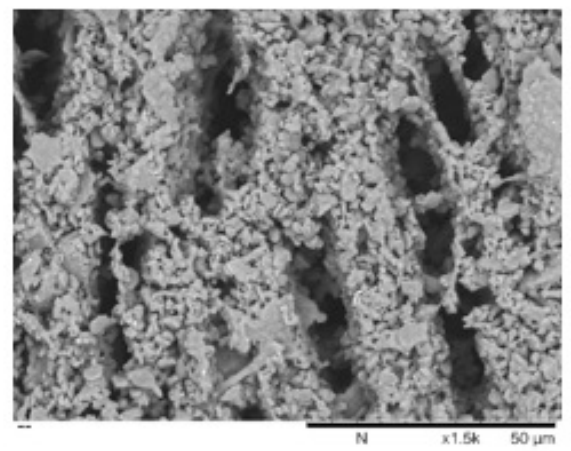

(a)

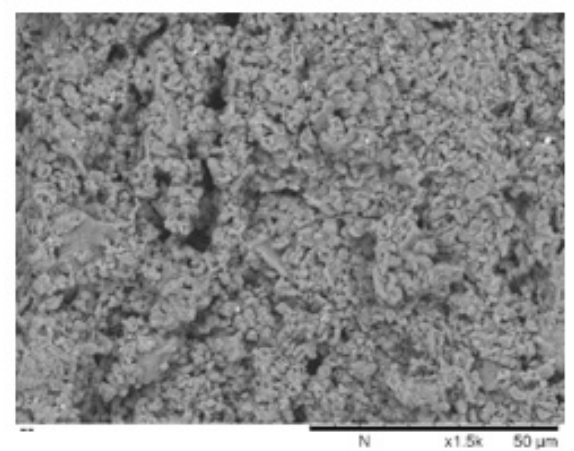

(b)

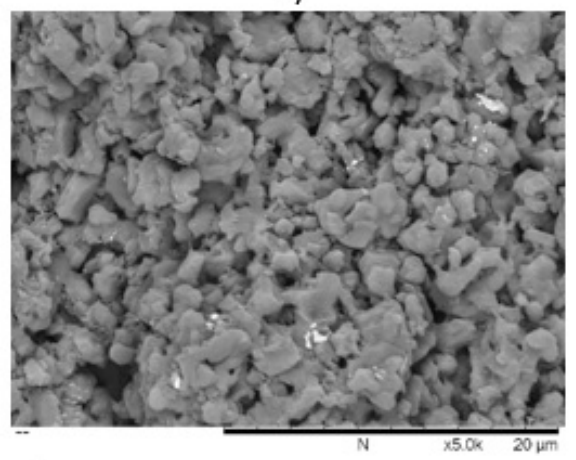

(c)

Figure 6. SEM micrographs of the outer and inner (fractured) surfaces of impregnated samples: A) outer, B) inner and C) inner with agglomeration. 
To prove that this agglomeration is really silver, EDS was used to provide rapid semiquantitative analysis of elemental composition. Figure 7 shows the micrograph with the area, fracture, from where EDS was performed. First, a square area was chosen where an homogeneous distribution was present (Figure 8A); then, a dot corresponding to an area of agglomerated nanoparticles was also analyzed (Figure $8 \mathrm{~B}$ ), Table 1 shows the results of elemental analysis.

EDS was also used to build up profile maps to see the distribution of silver nanoparticles on the surface and bulk of the samples. Figures 9 and 10, outer

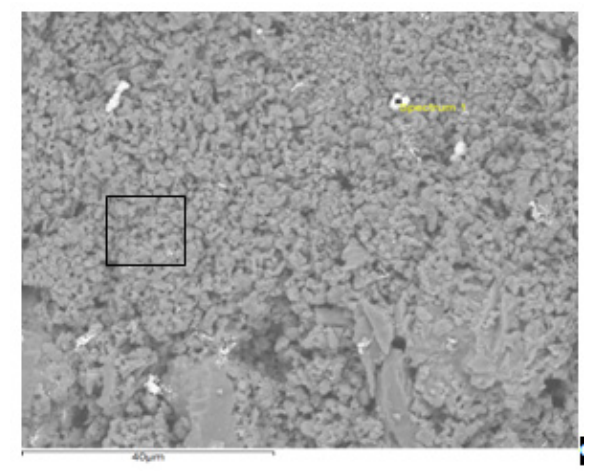

Figure 7. SEM micrograph with the internal (fractured) area from where EDS was done.

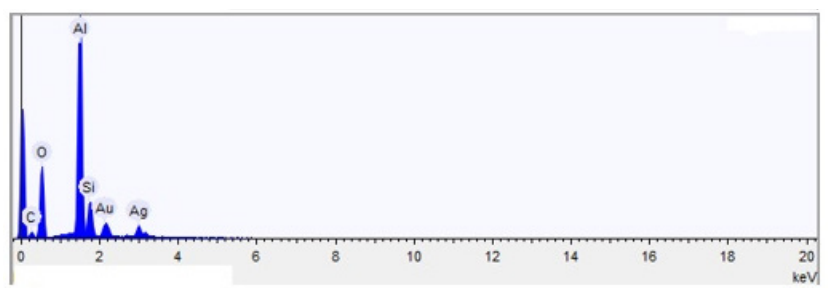

A)

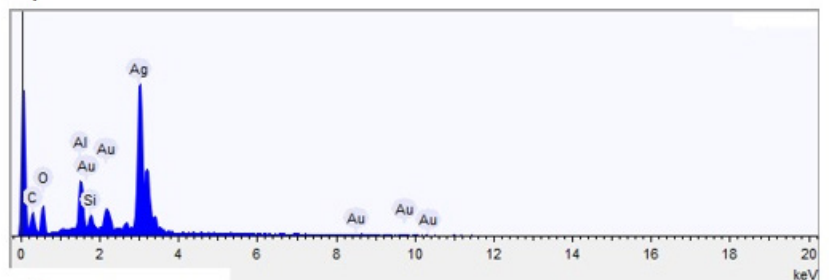

B)

Figure 8. EDS elemental analysis in: A) area of homogeneous distribution (square), B) area of nanoparticle agglomeration (dot).

Table 1. EDS elemental analysis of the area of: A) homogeneous distribution (square); and B) area of nanoparticles agglomeration (dot).

\begin{tabular}{|c|c|c|c|c|}
\hline \multirow{2}{*}{ Element } & A & B & $\mathbf{A}$ & B \\
\hline & \multicolumn{2}{|c|}{ Weight $\%$} & \multicolumn{2}{|c|}{ Atomic \% } \\
\hline Carbon & 10.299 & 7.150 & 17.744 & 20.545 \\
\hline Oxygen & 42.245 & 24.279 & 54.642 & 52.372 \\
\hline Aluminum & 27.645 & 5.195 & 21.202 & 6.645 \\
\hline Silicon & 6.032 & 1.453 & 4.445 & 1.785 \\
\hline Silver & 5.973 & 53.913 & 1.146 & 17.249 \\
\hline Gold & 7.805 & 8.010 & 0.820 & 1.404 \\
\hline
\end{tabular}

surface and inner (fractured) bulk, respectively, show the micrograph of the porous ceramic filter surface impregnated with silver nanoparticles (A), the map showing the silver distribution, where the white points represent the silver (B), and the way that these points (now red points to increase the visibility) are located in the structure $(\mathrm{C})$.

It is observed that the silver nanoparticles have a homogeneous distribution in the entire surface and fracture of the sample and the amount of nanosilver

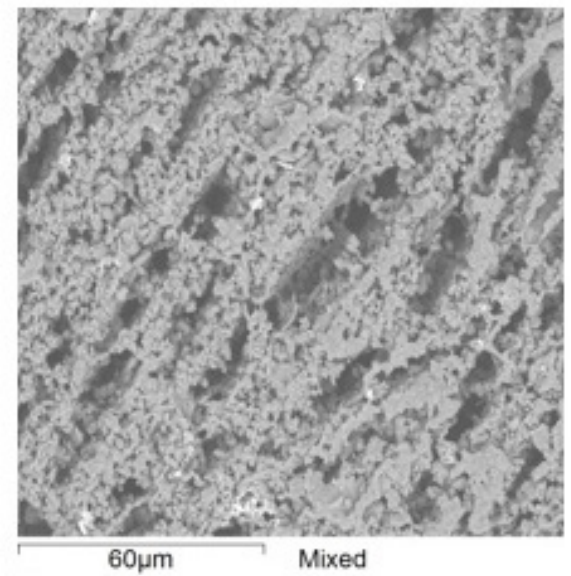

(a)

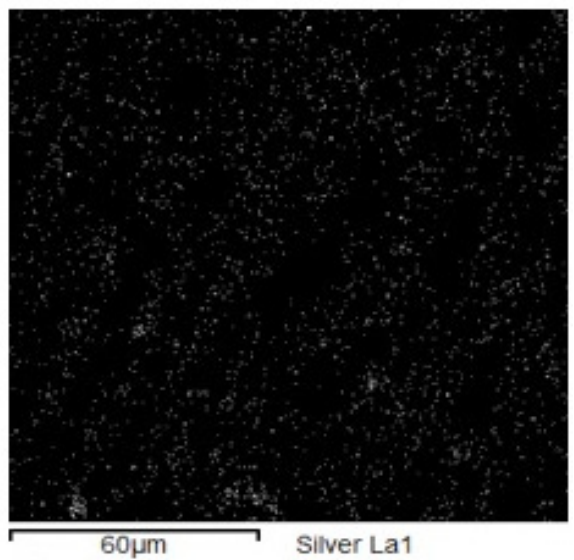

(b)

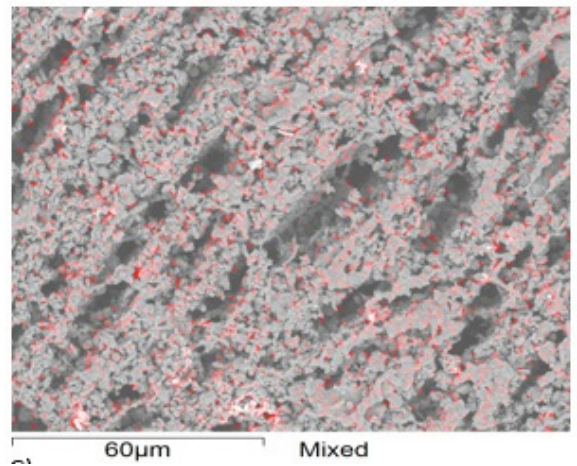

(c)

Figure 9. SEM/EDS of the sample external surface: A) micrograph; B) elemental map showing the silver distribution (white dots); C) silver element distribution (red dots to increase the visibility). 


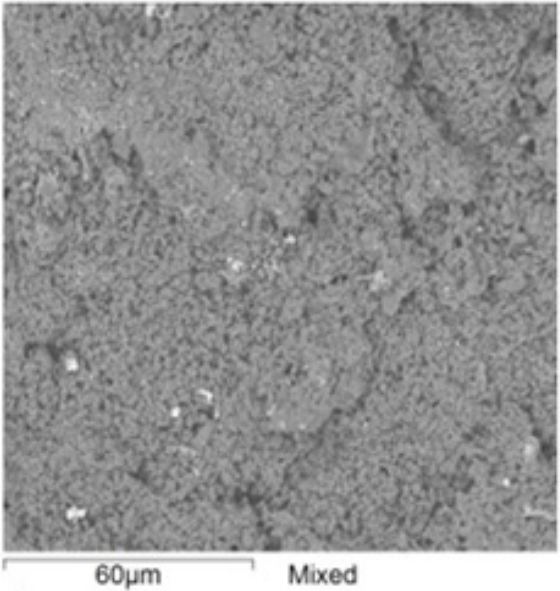

(a)

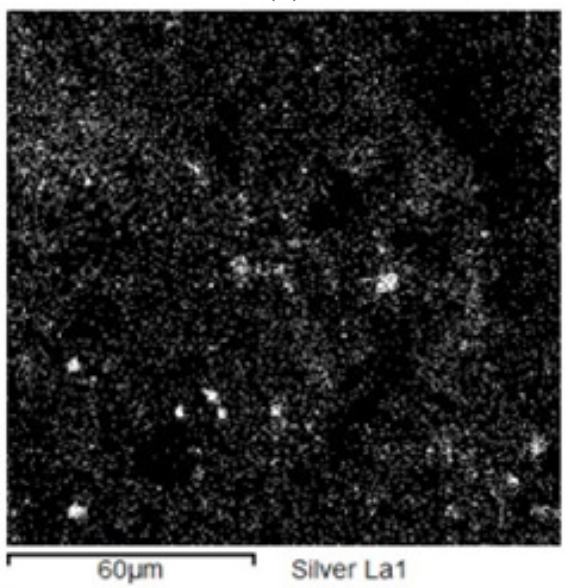

(b)

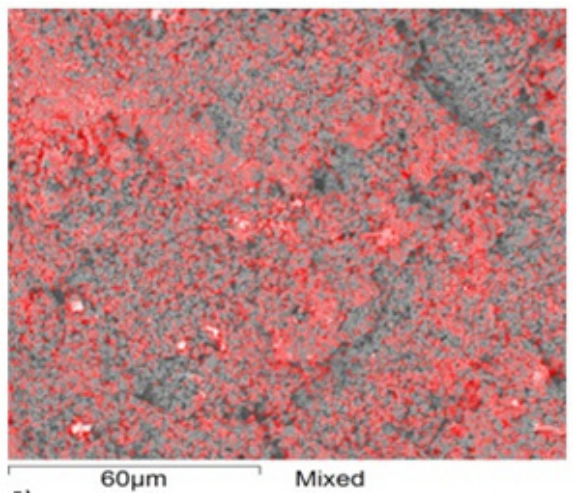

(c)

Figure 10. SEM/EDS of the sample fractured bulk: A) micrograph; B) elemental map showing the silver distribution (white dots); C) silver element distribution (red dots to increase the visibility).

is much higher in the inner part (bulk) of the fractured sample.

To test efficiency, the impregnation is correlated to the amount of nanosilver fixed in the sample and leached in water. The leached water after mechanical stirring (MS), centrifugation (CE) and ultrasonic bath (UL) was analyzed by GFAAS, to quantify the silver particles present, as shown in Table 2.
Table 2. Amount of silver in the different leached samples as detected by GFAAS.

\begin{tabular}{cc}
\hline Sample & $\begin{array}{c}\text { Concentration Ag } \\
(\boldsymbol{\mu g} / \mathbf{L})\end{array}$ \\
\hline MS 1 & 0.00963 \\
MS 2 & 0.00974 \\
MS 3-24 & 0.01783 \\
CE 15 & 0.00747 \\
CE 30 & 0.01755 \\
UL 5 & 0.04577 \\
UL 15 & 0.08292 \\
\hline
\end{tabular}

The results confirm that there is a very small amount of silver in the leached water. The initial suspension concentration was $1000 \mu \mathrm{g} / \mathrm{L}$; considering it all to be impregnated in the sample, it is possible to estimate that more than $99.99 \%$ of silver nanoparticles were fixed in the filter pellets.

According to CONAMA (Resolution 396/2008), Table 3 shows the list of parameters with the highest probability of occurrence in groundwater, their respective Maximum Allowed Values (MAV) for each of the uses considered as preponderant and the practicable quantification limits (PQL), considered as acceptable for the application of this Resolution (CONAMA 2008). The value of silver in the leached water is well below the value allowed by CONAMA.

According to WHO (World Health Organization):

- The retention rate of silver in humans and animals is under $10 \%$. The retained silver is mainly stored in the liver and skin. The half-life of silver in the liver is 50 days.

- Silver is occasionally found naturally in ground and surface water at $5 \mu \mathrm{g} / \mathrm{L}$.

- Average human intake of silver is $7.1 \mu \mathrm{g} / \mathrm{day}$.

- The acute lethal dose of silver nitrate is a minimum of 10 grams.

- Argyria is the only known human health effect of silver, and "is a condition in which silver is deposed on skin and hair."

Argyria has been described in syphilitic patients in poor health who were therapeutically dosed with a total of about $1 \mathrm{~g}$ of silver in the form of silver arsphenamine together with other toxic metals. There have been no reports of argyria or other toxic effects resulting from the exposure of healthy persons to silver. On the basis of present epidemiological and pharmacokinetic knowledge, a total lifetime oral intake of about $10 \mathrm{~g}$ of silver can be considered as the human NOAEL (NoObserved-Adverse-Effect Level). As the contribution of drinking water to this NOAEL will normally be

Table 3. Amount of silver allowed in groundwater. Adapted from CONAMA, 2008.

\begin{tabular}{cccc}
\hline \multirow{2}{*}{ Type } & \multicolumn{2}{c}{ MAV $(\mu \mathrm{g} / \mathrm{L})$} & PQL \\
\cline { 2 - 3 } & $\begin{array}{c}\text { Human } \\
\text { consumption }\end{array}$ & Recreation & $(\mu \mathrm{g} / \mathrm{L})$ \\
\hline Metallic silver & 100 & 50 & 10 \\
\hline
\end{tabular}


negligible, the establishment of a health based guideline value is not deemed necessary. On the other hand, special situations may exist where silver salts are used to maintain the bacteriological quality of drinking water. Higher levels of silver, up to $0.1 \mathrm{mg} / \mathrm{L}$ (a concentration that gives a total dose over 70 years of half the human NOAEL of $10 \mathrm{~g}$ ), could then be tolerated without risk to health (WHO, 2014). Considering the values of WHO, the quantity of silver in the leached water is well below the values allowed and it is without any risk to health.

The disc diffusion test (Kirby-Bauer antibiotic testing) was performed to detect if the silver nanoparticles present inhibitory and bactericidal effects. Table 4 shows the results of this test.

In this test, the antibiotic and the nanosilver present in the pellets stopped the bacteria from growing or even killed the bacteria, because there was an area around the pellets where the bacteria did not grow enough to be visible and a halo of inhibition was present. In the pellets without nanosilver, the halo of inhibition was absent. According to this, the filter pellets impregnated with nanosilver in this work showed strong inhibitory and bactericidal effects.

Table 4. Inhibition halo as detected by the Disc Diffusion Test.

\begin{tabular}{ccc}
\hline Bacteria & Samples & Inhibition halo \\
\hline \multirow{2}{*}{ Gram-negative } & Neomycin & Present \\
(Escherichia coli) & Pellet without Ag & Absent \\
& Pellet with Ag & Present \\
\hline \multirow{2}{*}{ Gram-positive } & Neomycin & Present \\
(Enterococcus faecalis) $)$ & Pellet without Ag & Absent \\
& Pellet with Ag & Present \\
\hline
\end{tabular}

\section{CONCLUSIONS}

Silver nanoparticle impregnation was very efficient, considering that around $99.9 \%$ of the initial silver was fixed in the filter pellets through an easy method of impregnation, such as dipping. Graphite furnace atomic absorption spectrometry was a suitable technique to quantify the silver in the leached water.

The silver nanoparticles were homogeneously distributed along the entire structure, both surface and fracture. SEM/EDS detected the presence of nanosilver throughout the pellets.

The pellets showed a strong bactericidal effect, according to the disc diffusion test, which indicated the presence of a halo of inhibition for the impregnated pellets with silver nanoparticles and absence of this halo in the pellets without silver.

\section{ACKNOWLEDGMENTS}

The authors thank CNPq for financial support (project numbers 401451/2012-7 and 229106/2013-7), and TNS for providing the silver nanoparticles. The authors declare that they have no conflict of interest.

\section{REFERENCES}

Adams, E., Schepers, R., Roets, E., Hoogmartens, J., Determination of neomycin sulfate by liquid chromatography with pulsed electrochemical detection. J. Chromatogr. A., 741, 233-240 (1996).

Alexander, J. W., History of the medical use of silver. Surgical Infections. Larchmt., 10, 289-292 (2009).

Amadio, T. M., Hotza, D., Rodrigues-Neto, J. B., Blosi, M., Costa, A. L., Dondi, M., Bentonites functionalized by impregnation with $\mathrm{TiO}_{2}, \mathrm{Ag}, \mathrm{Pd}$ and Au nanoparticles. Appl. Clay Sci., 146, 1-6 (2017).

Bal, A., Çepni, F. E., Çakir, Ö., Acar, I., Güçlü, G., Synthesis and characterization of copolymeric and terpolymeric hydrogel-silver nanocomposites based on acrylic acid, acrylamide and itaconic acid: investigation of their antibacterial activity against gram-negative bacteria. Braz. J. Chem. Eng., 32(2), 509-518 (2015).

Biemer, J. J., Antimicrobial susceptibility testing by the Kirby-Bauer disc diffusion method. Ann. Clin. Lab. Sci., 3, 2, 135-140 (1973).

CONAMA - Conselho Nacional do Meio Ambiente, RESOLUTION no 396, Water Quality. Brazil 396, 1, 64-68 (2008).

Dash, A., Singh, A. P., Chaudhary, B. R., Singh, S. K., Dash, D., Effect of Silver Nanoparticles on Growth of Eukaryotic Green Algae, Nano-Micro Letters, 4(3), 158-165 (2012).

Díaz-Soler, B. M., López-Alonso, M., MartínezAires, M. D., Nanosafety practices: results from a national survey at research facilities. J. Nanopart. Res., 19(5), 169 (2017).

Dong, F., Valsami-Jones, E., Kreft, J., New, rapid method to measure dissolved silver concentration in silver nanoparticle suspensions by aggregation combined with centrifugation. J. Nanopart. Res., 18, 259 (2016).

Duncan, T. V., Applications of nanotechnology in food packaging and food safety: barrier materials, antimicrobials and sensors. J. Colloid. Interface Sci., 363, 1-24 (2011).

Holcombe, J. A., Encyclopedia of Analytical Chemistry. John Wiley \& Sons, Ltd (2006).

Holt, J. G., Krieg, N. R., Sneath, P. H. A., Staley, J. T, Williams, S. T., Bergey's Manual of Determinative Bacteriology, 9rd ed. Lippincott Williams \& Wilkins. pp 11 (1994).

Hudzicki, J., Kirby-Bauer disk diffusion susceptibility test protocol. ASM (2009). 
Ju, C., Yen, Y., Li, S., Hsu, T., Yang, J., Ferulic acidmediated protection against neomycin-induced hair cell loss in transgenic zebrafish. J. Funct. Foods., 28, 157-167 (2017).

Leon-Silva, S., Fernandez-Luqueno, F., LopezValdez, F., Silver nanoparticles (AgNP) in the environment: a review of potential risks on human and environmental health. Water, Air, \& Soil Pollution, 227(9), 306 (2016).

Mackevica, A., Olsson, M. E., Hansen, S. F., Silver nanoparticle release from commercially available plastic food containers into food simulants. J. Nanopart. Res., 18(1), 5 (2016).

Mohanty, A., Physiochemical and antimicrobial study of polyherbal. Pharmacie globale., 1(4), 1-3 (2010).

Nam, G., Rangasamy, S., Purushothaman, B., Song, J. M., The Application of Bactericidal Silver Nanoparticles in Wound Treatment. Nanomater. Nanotechno., 5, 5-23 (2015).

NCCLS - National Committee for Clinical Laboratory Standards, Performance standards for antimicrobial disk susceptibility tests, 7rd ed. Approved standard M2-A7. National Committee for Clinical Laboratory Standards, Wayne, $\mathrm{Pa}$ (2000).

Olivier, T., Skurnik, D., Picard, B., Denamur, E., The population genetics of commensal Escherichia coli. Nat. Rev. Microbiol., 8(3), 207-217 (2010).

Russell, J. B., Jarvis, G. N., Practical mechanisms for interrupting the oral-fecal lifecycle of Escherichia coli. J Mol. Microbiol. Biotechnol., 3(2), 265-272 (2001)
Ryan, K. J., Ray, C. G., Sherris Medical Microbiology, 4rd ed., McGraw Hill, pp 294-295 (2004).

Shahzada, H., Shehzada, S., Shireen, F., Naz, S., Epidmological and sensitivity patterns of specified antibiotics inimical to pathogens causing urinary tract infections (UTIs). Int. J. Adv. Res., 2(3), 586589 (2014).

Singh, R., Nalwa, H. S., Medical applications of nanoparticles in biological imaging, cell labeling, antimicrobial agents, and anticancer nanodrugs. J. Biomed. Nanothecnol., 7, 489-503 (2011).

Singleton, P., Bacteria in Biology, Biotechnology and Medicine, 5rd ed., Wiley, pp 444-454 (1999).

Sondi, I., Salopek-Sondi, B., Silver nanoparticles as antimicrobial agent: a case study on E. coli as a model for Gram-negative bacteria, Silver nanoparticles as antimicrobial agent: a case study on E. coli as a model for Gram-negative bacteria. J. Colloid Interface Sci., 275, 177-182 (2004).

Stoimenov, P. K., Klinger, R. L., Marchin, G. L., Klabunde, K. J., Metal oxide nanoparticles as bactericidal agents. Langmuir, 18, 6679-6686 (2002).

WHO - World Health Organization, Silver in Drinkingwater Background document for development of WHO. Guidelines for Drinking-water Quality, WHO, Geneva (2014). 